\title{
Comissão de Acumulação de Cargos
}

\section{PROCESSO $\mathrm{N}^{\circ} 5.712-66$}

Pedido de reconsideração out tecurso de decisão do Diretor-Geral do DASP firmada em parecer desta Comissão não tem efeito suspensivo, conforme o que dispóe o art. 168 da Lei $n^{\circ} 1.711$, de 28 de outubro de 1952.

\section{PARECER}

O Magnifico Reitor da Universidade Federal de Juiz de Fora consulta se tem efeito suspensivo o recurso ao Presidente da República de decisão do Diretor-Geral do Departamento Administrativo do Serviço Público (DASP) ao aprovar parecer desta Comissão de Acumulação de Cargos.

2. Aduz o ilustre consulente que vem admitindo aquêle efeito, dentro da orientação recebida, até agora, do $\mathrm{Mi}$ nistério da Educação e Cultura e do próprio DASP, porém desejaria fôsse confirmado o acêrto da tal procedimento.

3. Com efeito, somos sabedores que essa tem sido a norma seguida, ao que nos parece, por quase todos os órgãos da Administração, com referência às decisôes do Diretor-Geral do DASP baseadas em pareceres desta Comissão. Não assim com referência à decisão final do Presidente da República.

4. Até certo ponto, cremos nós, explica-se o procedimento da Administração. Como em quase tôdas as hipóteses de acumulação há um cargo de professor, se a decisão contrária fôr dada no decurso do ano letivo, e tendo ela efeito imediato criará fatalmente uma solução de continuidade nas aulas, tumultuando o ensino e em nada beneficiando à Administração. Não é só: existe a circunstância especial de que esta Comissão, ela própria, aprecia as razóes dos pedidos de reconsideração dirigidos ao Diretor-Geral do DASP ou as dos recursos endereçados ao Presidente da República. Ninguém desconhece que, na esfera administrativa federal, há sòmente duas autoridades competentes para decidirem sôbre assunto de acumulação de cargos: o Diretor-Geral do DASP e o Presidente da República, êste em grau de recurso. Acresze, porém, que além da comissão de professôres a que se refere o $\S 1^{\circ}$, do art. 26 , da Lei número $4.881-\mathrm{A}$, de 6 de dezembro de 1965 (Estatuto do Magistério Superior), e que só cuida do exame da correlação de matérias, só há um órgão de competência privativa para examinar assunto de acumulação e sôbre êle emitir parecer. A Consultoria Juridica do DASP ou a Consultoria-Geral da República só opinam excepcionalmente sôbre a matéria quando solicitada, a primeira, pelo Diretor-Geral do DASP; a segunda, pelo Presidente da República não raro por sugestão da própria Comissão de Acumulação de Cargos. Em face dessas cirzunstâncias peculiares, há como que úma presunção, em certo sentido procedente, de que a Comissão de Acumulação de Cargos não perde, normalmente, sua jurisdição até que o processo seja decidido afinal pelo Presidente da República. Normalmente porque excepcionalmente, como dissemos, a Consultoria Jurídica do DASP ou a Consultoria-Geral da República pode adquirir essa jurisdição, quando o pronunciamento de uma ou dé outra é solicitada. Não havendo, assim, transferência ou transmissão de conhecimento do assunto a outro órgão, entendeu-se que haveria efeito devolutivo, a exemplo do que ocorre na sistemática processual civil.

5. Por isso dissemos que, até certo ponto, o procedimento da Administração 
se explica, embora a rigor isso não se justifique pois que temos lei que disciplina $o$ assunto.

\section{Legem habemus}

6. Sem dúvida, assim dispõe o artigo 168 da Lei n 1.711 , de 28 de outubro de 1952 (Estatuto dos Funcionários):

«Art 168. O pedido de reconsideração e o recurso não têm efeito suspensivo; o que fôr provido retroagirá nos efeitos à data do ato impugnado».

7. Essa é a lei! Assim, a decisão do Diretor-Geral do DASP, ao aprovar parecer desta Comissão de Acumula. ção de Cargos, tem efeito imediato, na forma da lei, que não abriu qualquer exceção de conveniência ou oportunidade não ensejando a linguagem do texto ou tro alcance que não aquêle do sentido evidente, claro é implacável!

Durum jus, sed ita lex scripta est!

$\mathrm{E}^{\prime}$ o que nos parece, salvo mais autorizado juizo.

C.A.C. 27 de setembro de 1966 . - Corsindio Monteiro da Silva, Relator. - José Medeiros. - Hilton de Carva. tho Briggs. - Célio Fonseca. - Plinio de Carvalho Werneck.

Submeto nos têrmos do $\S 3^{\circ}$ do artigo 15 , do Decreto $\mathrm{n}^{\circ} 35.956$, de 2 de agôsto de 1954 , o presente parecer à aprovação do Senhor Diretor-Geral do
DASP.

Brasilia, 30 de setembro de 1966 . José Medeiros, Presidente da Comissão de Acumulação de Cargos.

De acôrdo. Restitua-se à Universidade Federal de Juiz de Fora. Em 5-10 1966. - Luiz Vicente B. de Ouro Prêto, Dire-
tor-Geral.

\section{PROCESSO $\mathrm{N}^{\circ} 7.107-66$}

O funcionário amparado pelá Lei $\mathrm{n}^{\circ} 1.741$, de 1952 , e na condição de «agregado» com vencimento de cargo em comissão, está abrangido pela norma proibitiva de acumular, inscrita no art. 185 da Constituição.

\section{PARECER}

A Comissão de. Desenvolvilmento do Vale do Jequitinhonha, entidade autár- quica do Estado de Minas Gerais, consulta a esta Comissão se «funcionário público federal, amparado pela Lei número 1.741-52, agregado, pode - enquanto não fồ aproveitado em cargo equivalente na forma da Lei 1.741-52 - ser admitido como Assessor desta Autarquia pelo regime da C.L.T. sem incidir em acumulação proibida?»

2. A mencionada entidade fundamenta a consulta no fato de ocorrer a agregação «apenas com o símbolo sem o cargo $\left(\$ 33^{\circ}\right.$ do art. 15 do Decreto 48.921-8-960-D. O. de 13 de setembro de 1960 ) e a conclusão de que «os funcionários agregados não ocupam cargos» ( $D$. . O. de 26-1-65, página 955 Proc. 13.305-64 - DÁSP - Divisão de Regime Juridico de Pessoal) e mais a crrzunstância de permanecer o agregado inativo, enquanto não aproveitado em cargo equivalente ao simbolo com que foi agregado, consoante entendimento da Consultoria-Geral da República fixado no item 8 do seu Parecer $n^{\circ} 259-\mathrm{H}$, de 25 de outubro de 1965 publicado no D. O. de 30 de novembro de 1965».

3. De logo, cabe ressaltar a situaçăo peculiar do funcionário amparado pr la Lei $\mathrm{n}^{\circ} 1.741$, de 1952 : em razão do exercicio de cargos em comissão por um periodo ininterrupto de 10 anos, a êle fica assegurado o direito de continuar percebendo o vencimento de cargo em conissão, até ser aproveitado em outro equivalente. Nessa hipótese, fica o funcionário na condição de agregado, entendendo o $\mathrm{Sr}$. Consultor-Geral da República que a «agregação não implica ém disponibilidade eterna. Pelo contrário, a Administração deve, de imediato, prozurar regularizar a situação do ağregado, aproveitando-o em cargo compativel com o da comissão, pois a presunção é de que se trata de servidor com elevado grau de conhecimento e experiência no trato da coisa pública, motivo pelo qual seu não aproveitamento importa em sensivel prejuizo para o Poder Público» (Parecer de referência número 132-H, aprovado pelo Senhor Presidente da República e publicado no Diário Oficial de 28 de jane ro de 1965).

4. Essa circunstância, no entanto. não exclui o funcionário amparado pela Lei $\mathrm{n}^{\circ} 1.741$, de 1952 , da norma cons- 
titucional que proibe a acumulação de cargos. De fato, êsse preceito proibitivo abrange, indistintamente, o servidor ativo e o inativo, inclusive o aposentado, conforme esta Colmissão procurou demonstrar, exaustivamente, no Parecer emitido no processo DASP $\mathrm{n}^{\circ} 13.403-63$, com fundamento no preceito inscrito no art. 185 da Constituição, na ação do poder regulamentar, na orientação administrativa, com a ratificação dos julgados dos mais elevados órgãos judiciais.

5. Diante do exposto, deve ser respondida negativamente a consulta exposta no item inicial dêste parecer.

C.A.C., 28 de setembro de 1966 . José Medeiros, Relator. - Hilton de Carvalho Briggs. - Célio Fonseca. Corsindio Monteiro da Silva. - Plinio de Carvalho Werneck. - José Maria dos Santos Arauijo Cavalcânti.

Submeto nos têrmos do $\S 3^{\circ}$ do artigo 15 do Decreto $\mathrm{n}^{\circ} 35.956$, de 2 de agôsto de 1954 , o presente parecer à aprovação do Senhor Diretor-Geral do DASP.

Brasilia, 29 de setembro de 1966. José Medeiros, Presidente da Comissão de Acumulação de Cargos.

Aprovado. Em 10-10-66. - Luiz Vicente B. de Ouro Prêto, Diretor-Geral.

\section{PROCESSO N $\mathrm{N}^{\circ} 2.635-65$}

\section{PARECER}

Após havermos relatado o presente processo de interêsse do Professor José Pedro Pinto Esposel, Escriturário do Banco do Brasil, letra $\mathrm{F}$, com atribuiÇões próprais de Documentarista, exercidas na Seção de Arquivo e Expediente da Agência Central do Rio de Janeiro, e ocupante do cargo de Professor Assistente junto à Cadeira de «Introdução ao Estudo da História», da Faculdade de Filosofia, Ciência e Letras, da Universidade Federal Fluminense, em que concluimos pela possibilidade legal da acumulação de ambos aquêles cargos, foi o nosso parecer aprovado pela unanimidade desta Comissão de Acumulação de Cargos, e, afinal, pelo Senhor Diretor-Geral do Departamento Administrativo do Serviço Público.

2. Acontece, porém, que o Departamento do Funcionalismo do Banco do
Brasil S. A., através de ofício assinado pelos Srs. José Fontes Ferreira e André O. G. de Albuquerque, se permitiu devolver o Processo ao Senhor DiretorGeral do DASP, para solicitar nôvo pronunciamento desta Comissão «em faze dos esclarecimentos que agora prestamos com vistas a fornecer subsidios corretos para exame de matéria ali versada», havendo sido o processo a mim novamente distribuido para reexame e parecer.

3. Aduzem os signatários do ofício que o interessado «foi admitido no quadro de escrita dêste Banco para exercer quaisquer tarefas, não técnicas», e que o cargo, em comissão, de Investigador de Cadastro, exercido pelo interessado na Agência Centro do Rio de Janeiro, «tem como função específica informar - Banco sôbre a situação econômico-financeira de algum cliente, para que a Administração, independentemente de conhecimento direto ou pessoal, possa julgar com segurança pedidos de crédito que lhe são propostos», sendo de demissibilidade ad rutum. Alegam, ainda, que o Banco do Brasil S. A. não tem cargo de Documentarista ou Arquivista.

4. Nosso parecer baseou-se em critérios fixados por esta Comissão, já de longa data, para o exame dos pressupostos legais que informam a acumulaçăo de cargos em que incidem servidores do Banco do Brasil S. A. Tais critérios foram firmados em face da situação peculiar dos servidores daquele estabelecimento de crédito, lastreando-se nos critérios de promoção e acesso aos postos da carreira do servidor do Banco do Brasil S. A., conforme informação prestada a esta Comissão, pela própria Direção-Geral daquele estabelecimento de crédito reafirmada no Ofício FUNCI 49.385-65 - de 13 de janeiro de 1966, e constante do Parecer no Processo número $3.340-65-\mathrm{DASP}$, aprovado pelo Senhor Diretor-Geral de 25 de fevereiro de 1966. Neste últiłmo parecer, reafirmamos o entendimento anterior de que da letra $\mathrm{F}$ em diante, o Escriturário do Banco do Brasil S. A., por ter tarefas ou encargos de maior relevância e complexidade, teria possibilidade de ser considerado cargo de natureza técnica ou cientifica (Vide Parecer in Pracesso $\mathrm{n}^{\circ} 6.221-62$, publicado no Diário Oficial de 22 de outubro de 1962). 
5. Demais disso, o parecer que emitiłmos se baseou em declarações oficiais prestadas pela Agência Centro do Rio de Janeiro (Seção do Funcionalismo) ficando desde logo esclarecido que todos os processos que esta Comissão tem examinado referentes às acumulações de servidores do Banco do Brasil S. A. são instruidos com base em elementos fornecidos pelas respectivas agências locais e nunca pela Direção-Geral, jamais tendo sido levantada qualquer dúvida sôbre a autenticidade ou correção de qualquer dessas declarações, sendo a primeira vez que isto acontece, pelo menos nestes dez anos que mourejo nesta Comissão. Jamais, inclusive, testemunhei, salvo no presente caso, que uma declaração feita pelos responsáveis de qualquer Agência do Banco do Brasil S. A., com referência a servidores que nela servem em tełmpo algum, fôsse desautorada ou considerada incorreta pela Direção-Geral daquela entidade.

6. Demais disso, muito pouco aproveitam os pretensos esclarecimentos trazidos, a não ser cópia da fé-de-oficio do

Faz-se mister aduzir que o que os signatários do oficio chamam de squadro de escrita» é o constantemente chamado, em outros processos, de «quadro de conta-
bilidade», integrado por Escriturários -
desde o Escriturárion desde o Escriturário Inicial até o Escriturário Letra I, senão mesmo até os últimos postos da Carreira, vale dizer, aos de Conferente de Seção, Subchefé de Seção e Chefe de Seção, a que o Escriturário pode alçar-se pelo exclusivo

8. Não ignoramos que ai não se exaure o quadro do funcionalistno do Banco do Brasil S. A., que possui, à Engenheiros quadro técnico, constituido de além de um Advogados, Médicos, etc., de profissionais Carpinteiros etc.).

9. Quando esta Comissão de Acumulação de Cargos classifica como técnico um cargo de Escriturário do Banco do Brasil S. A., faz isso dentro do critério estabelecido, de verificação das atribuições conferidas ao Escriturário da letra aplicação aplicação do regime de acumulação de cargos. E' evidente que o fato de esta Comissão conceituar um cargo de Escriturário do Banco do Brasil S. A. como técnico não implicará, necessàriamente, em fazer reconhecer que o detentor do cargo faz juz a ingressar no chamado quadro-técnico daquele estabelecimento de crédito.

10. O caso dêste Processo é o de um Escriturário da letra $\mathrm{F}$ a quem foram cometidas tarefas que, no seu conjunto, esta Comissão entendeu serem de natureza técnica ou cientifica, nos tẻrmos do art. $3^{\circ}$ do Decreto número 35.956 , de 2 de agôsto de 1964 , e para exclusivo efeito de apreciação dos requisitos exigidos por lei para a possibilidade de exercer o servidor um outro cargo público de magistério.

11. A conceituação da tecnicidade do cargo para efeito de acumulação é da competência desta Comissão, se se trata de cargo não definido legalmente como tal, e se esgota no âlmbito administfativo no único efeito de aplicação das regras de exceção à no:ma geral de vedação de acumular. E a tecnicidade é revelada a critério desta Comissão, à vista das atribuições confiadas ao servidor e com observância dos pressupostos contidos no artigo $3^{\circ}$ do Decreto número $35: 956$, de 2 de agôsto de 1954 , conforme um sem número de pareceres que êste colegiado vem emitindo em repetida, remastigada e estafante jurisprudência.

12. E a classificação como técnico se dá fora do chamado quadro-técnico do Banco do Brasil S. A. tanto quanto, na própria Administração direta, em que há um sistema de classificação de cargos, se prozessa além dos cargos que se inscrevem no Grupo Ocupacional TC (técnico-científico) da Lei número 3.780 , de 12 de julho de 1960 , tais como Assistente de Pesquisas, Assistente de Farmacêtutico, Assistente Judiciário, Auxiliar de Pesquisas, Bioquimico, Cartógrafo, Cenarista, Curador, Desenhista, Diplomata, Enologista, Estéreo-Cartógrafo, Geógrafo, Geoquímico, Gravador da Casa da Moeda, Inspetor da Defesa Sanitária, Inspetor de Ensino, Naturalista, Parasitologista, Perito em Belas Artes, Psicólogo, Técnico de Administração, Técnico de Educação, Zootecnista. São cargos, todos êsses, que 
não pertencem ao Grupo Ocupacional técnico-científico da Lei número 3.780 , de 1960 , embora alguns dêles já tenhạm sido assim considerados por lei nova, e que, no entanto, já eram considerados, por esta Comissão, como de natureza técnica ou cientifica para efeito de acumulação de cargos nos têrmos da conceituação dada pelo artigo $3^{\circ}$ do Decreto número 35.956 de 2 de agôsto de 1954 , sendo de notar que isto nunca serviu de razão bastante para classificá-los como técnico-cientifico nos têrmos da Lei de Classificação de Cargos.

13. Ora, admitimos que os encargos, atribuições ou tarefas cometidos ao interessado neste processo eram de natureza técnica ou científica, para efeito de acumulação, em face de informações idôneas fornecidas pelo próprio Banco do Brasil S. A., em janeiro de 1965 , sem que em lugar nenhum, do nosso parecer, afirmássemos que aquêle estabelecimento de crédito tenha, ou haja tido, cargo de Documentarista ou de Arquivista. O que afirmamos e aqui reafirmamos é que ao Escriturário, letra $\mathrm{F}$, com atribuições próprias de Documentarista, na Seção de Arquivo e Expediente, na Agência Centro do Rio de Janeiro, poder-se-ia considerar, para efeito de acumulação, como no exercício de cargo de natureza técnica ou cientifica. E, agora, ainda assim o consideramos. E um Escriturário, letra $\mathrm{F}$. de reconhecida qualificação, que trabalha na Seção de Arquivo na Agência Centro do Rio de Janeiro, pode ser ocupado com tarefas ou encargos próprios de Arquivista ou Do cumentarista, embora sem ocupar cargos dêsses nomes ou assim cer nezessàriamente chamado. Nem parece razoável que o Banco do Brasil S. A. que, ao que se diz, tem em alta conta o critério do mérito, iria ocupar um Escriturário, letra $\mathrm{F}$, com 14 anos de casa, que pode ser Subgerente de Agência, Encarregado de Câmbio de Agência de $3^{2}$ Classe, Chefe de Serviço de Agência de $1^{a}$ ou de $2^{7}$ Classe, Procurador ou Chefe de Sẹcretaria, ou dêstes postos mínimos para cima, para exercer tarefas singelas e de nenhuma complexidade, como pretende fazer crer o Ofício da Direção-Geral daquele estabelecimento de crédito, quando pelas Anotações, que é uma espécie de fé-de-ofício, trazidas à colação, a pró- pria Direção-Geral revela que o Banco do Brasil S. A. não desconhecia que êsse Escriturário é portador de diploma de Bacharel em Direito, desde 1965. de diploma de Bacharel em Geografia e História, pela Faculdade Fluminense de Filosofia, desde 1959, e de Licenciado nas mesmas disciplinas pela mesma Faculdade, desde 1960.

14. Pelo que nos parece, porquanto não atinamos com o que possa prejudicar ao Banco se o seu servidor der aulas à noite em uma Faculdade quando esta Comissão já entendeu que isso é regular, parece-nos que o que ensejou êste pedido de nôvo pronunciamento, fato inédito nesta Comissão, pois que insinua uma decisão contrária ao interêsse do servidor com a reforma de uma decisão favorável, é um lastimável mal-entendido ou a preocupação de evitar que o interessado possa pleitear, futuramente, ser considerado como ocupante de cargo de quadro técrico, em que se incluiria o de Documentarista. E até é de estranhar que só agora se manifeste essa dúvida, quando se sabe que o servidor do Banco, do quadro «não técni zo», é sempre Escriturário, e a caracterização que suas atribuições lhe emprestam, e que esta Comissão reconhece, é sòmente para efeito de aplicação das regras de exceção à norma geral de proibição će acumular cargos públicos. Assim tem decidido o Diretor-Geral do DASP, em inúmeros casos, firmado em pareceres dêste colegiado.

15. Acresce que, em documento anexado ao Processo, o Banco Central da República do Brasil informa que o interessado, Professor José Pedro Pinto Esposel, foi requisitado do Banco do Brasil S. A. e presta serviços àquele órgão no pôsto efetivo. no Arquivo Geral da Seção de Serviços Diversos da Divisão de Serviços Gerais, do Departamento Administrativo, no horário de 12 às 18 horas, «competindo-lhe a classificação, seleção, conservação e guarda cie documentos, organização do sistema de fichários, preparo de índices, relações e referências, análises e descrição do conteúdo de documentos, contrôle das requisições, elaboração do arranjo e inventário, além de outras tarefas relacionadas com a documentação em geral». Êsse documento está assinado em conjunto pelo 
Senhor Arthur Mário dos Reis Braga (Departamento Administrativo), e pelo Senhor Roberto José Horta Mourão (Divisão do Pessoal) e anexada a f. 21 do presente processo.

16. Destarte não houve sequer solução de continuidade nas atribuições cometidas ao interessado que teria certamente sido requisitado pelo Banco Central da República do Brasil em razão de suas habilitações especificas.

17. Não vê o Relator, por via de conseqüência, como reconsiderar seu ponto de vista, ratificando, assim, o parecer que emitiu favoràvelmente à acumulação do Professor José Pedro Pinto Esposel, baseado em informaçŏes idôneas oferecidas pelo próprio Banco do Brasil S. A. (Agência do Centro - GB), em janeiro, de 1965, e agora confirmadas pela informação prestada pelo Banco Central da República do
Brasil.

18. Faz-se mister notar que o processo resultou de consulta formulada pelo próprio interessado ao pretender legalizar sua situação como Professor na Faculdade de Filosofia Ciências e Letras, da Universidade Federal Fluminense.

C.A.C., 26 de agôsto de 1966. Corsíndio Monteiro da Silva, Relator - José Medeiros - Hilton de Carvalho Briggs - Célio Fonseca - Plinio de Carvalho Werneck - José Maria dos Santos Araújo Cavalcanti - Ladisiau Godofredo Dias Carneiro Netto.

Submeto nos têrmos do $\S 3^{\circ}$ do artigo 15, do Decreto $\mathrm{n}^{\circ} 35.956$, de 2-8-54, o presente parecer à aprovação do $\mathrm{Se}-$ nhor Diretor-Geral do DASP.

Brasilia, 8 de setembro de 1966 . José Medeircs, Presidente da Comissão de Acumulação de Cargos.

Aprovado. Em 26 de setembro de 1966. - Luiz Vicente B. de Ouro Prêto,
Diretor-Geral. 